\title{
Особливості взаємодії декількох протоколів маршрутизації у складній комп'ютерній мережі
}

\author{
I. С. Бобрікова ${ }^{\bowtie}$, T. Н. Барабаш \\ Одеська національна академія харчових технологій, вул. Канатна, 112, м. Одеса, 65039, Україна \\ \e-mail: bobrikova.irina@gmail.com
}

\begin{abstract}
В роботі представлено дослідження особливостей функиіювання декількох протоколів марирутизачії одночасно на одному маршрутизаторі та особливостей налаштування такої взаємодії. Робота проводилась у середовищі Cisco Packet Tracer. Вивчено налаштування маршрутизаторів у різних варіантах побудови складних мереж з функиіюванням декількох протоколів маршрутизації та проведено спостереження, яким чином певна настройка впливає на побудову таблиці мармрутизацї.
\end{abstract}

Ключеві слова: Маршрутизатор; Протокол маршрутизаиії; Складні мережі; Cisco Packet Tracer

(C) The Author(s) 2017. This article is an open access publication

This work is licensed under the Creative Commons Attribution 4.0 International License (CC BY) http://creativecommons.org/licenses/by/4.0/

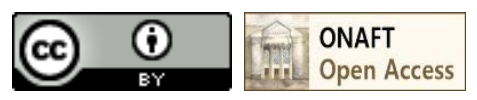

\section{Основна частина}

За замовчуванням кожен протокол маршрутизації, що працює на певному маршрутизаторі, поширює тільки «власну» інформацію, тобто ту інформацію, яка була отримана даним маршрутизатором 3 даного протоколу. Наприклад, якщо про маршрут до деякої мережі маршрутизатор дізнався по протоколу RIP, то i поширювати по мережі оголошення про цей маршрут він буде за допомогою протоколу RIP.

Однак такий режим роботи маршрутизаторів ставить невидимі бар'єри на шляху поширення маршрутної інформації, створюючи у складі мережі області взаємної недосяжності. Завдання маршрутизації вирішувалося б ефективніше, якби маршрутизатори могли обмінюватися маршрутною інформацією, отриманою різними протоколами маршрутизації. Така можливість реалізується в особливому режимі роботи маршрутизатора, що називається перерозподілом. Цей режим дозволяє одному протоколу маршрутизації використовувати не тільки «свої», але й «чужі» записи таблиць маршрутизації, отримані за допомогою іншого протоколу маршрутизації, зазначеного при конфігурації (рисунок 1).

\section{Перерозподілена маршрутна інформація}

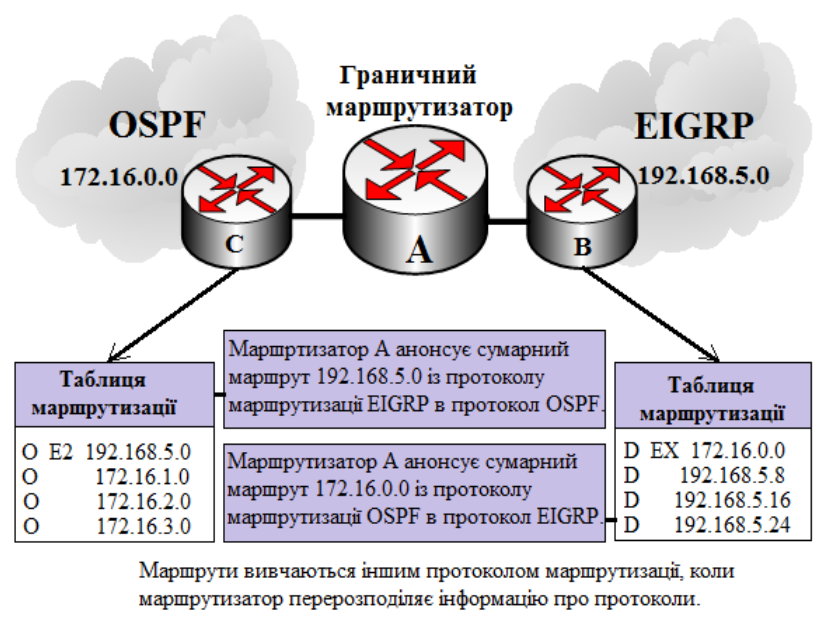

Рисунок 1 - Перерозподілена маршрутна інформація
Маршрутизатори можуть перерозподіляти статичні і безпосередньо підключені маршрути так само, як i маршрути від інших протоколів маршрутизації.

Перерозподіл завжди здійснюється назовні. Маршрутизатор, який робить перерозподіл, ніколи не змінює свою таблицю маршрутизації. Коли відбувається перерозподіл між OSPF і EIGRP, OSPFпроцес на граничному маршрутизаторі бере $E I G R P$ маршрути з таблиці маршрутизації і поширює їх $O S P F$ сусідам. Точно так само EIGRP-процес на граничному маршрутизаторі бере $O S P F$-маршрути 3 таблиці маршрутизації і поширює їх EIGRP-сусідам. Тоді обидві автономні системи знають про маршрути іншої системи, і кожна автономна система може прийняти рішення про маршрутизацію в цій мережі.

Крім того, велику складність представляє собою узгодження різних метрик, які використовують в своїх алгоритмах маршрутизації різні протоколи.

Коли маршрутизатор рекламує з'єднання, підключене до одного зі своїх інтерфейсів, початкову метрику називають метрикою за замовчуванням, і вона залежить від характеристик інтерфейсу: для $O S P F$ метрика за замовчуванням грунтується на пропускній здатності інтерфейсу, для $E I G R P$ - на пропускній спроможності i затримці. Для RIP метрика за замовчуванням починається 3 лічильника переприйомів, рівного 0, і зростає від маршрутизатора до маршрутизатора. Перерозподілені маршрути, фізично не підключені до маршрутизатора, вивчаються за допомогою інших протоколів. Тому виникає складність в перетворенні 3 однієї метрики в іншу: 3 кількості переприйомів в пропускну здатність. Якщо граничний маршрутизатор перерозподіляє інформацію між протоколами маршрутизації, він повинен вміти перетворювати метрику одного протоколу в метрику іншого протоколу.

Команда default-metric, яка використовується в режимі конфігурації протоколу маршрутизації, встановлює метрику за замовчуванням для всіх перерозподілених маршрутів. Маршрутизатори Cisco дозволяють встановлювати метрику за замовчуванням, як частину команди redistribution або в параметрі metric карти маршрутів. Але тут треба виконувати одну 
важливу умову: який би метод ми не вибрали для установки метрики за замовчуванням, іiі значення повинно бути більше, ніж найбільше значення метрики всередині автономної системи, щоб запобігти неоптимальній маршрутизації та петлям маршрутів.

Якщо маршрутизатор отримує інформацію про одного й того ж одержувача або мережі одержувача 3 різних джерел, то йому необхідно якимось чином вибрати, який саме маршрут помістити в таблицю. Для цього використовується адміністративна дистанція.

Administrative distance (AD) - це число, присвоєне кожному з можливих джерел маршрутів, яке є певною мірою довіри до джерела. У таблицю маршрутизації потрапить маршрут від того джерела, у якого менше значення $A D$. Адміністративна дистанція має тільки локальне значення i ніяк не впливає на прийняття рішення на інших маршрутизаторах.

Особливості функціонування і налаштувань маршрутизаторів, на яких одночасно працюють декілька протоколів маршрутизації, ми вивчаємо за допомогою програми-тренажеру CiscoPacketTracer. Програма PacketTracer $€$ інтегрованим, сумісним та візуалізованим середовищем, орієнтованим на починаючих мережних адміністраторів, що ставлять перед собою задачу набути навичок проектування, конфігурування та налагодження комп'ютерних мереж.

За допомогою цієї програми збираємо різні схеми і налаштовуємо на маршрутизаторах різні протоколи маршрутизації. У цій статті немає можливості показати налаштування усіх маршрутизаторів. Але вони були зроблені і були написані методичні вказівки для виконання лабораторних робіт для студентів спеціальності «Комп'ютерні системи та мережі».

Приклади. Схема 1. Побудова та налаштування мережі зі зміною адміністративної дистанції при взаємодії протоколів маршрутизації RIP та $O S P F$.

Будуємо мережу 3 використанням трьох маршрутизаторів, яким присвоїмо назви: $O S P F$ - той, на якому працюватиме протокол $O S P F, R I P$ - той, на якому працюватиме протокол $R I P$ та $A D$ маршрутизатор, який 3'єднуватиме два попередніх (рисунок 2). На останньому пристрої буде змінюватися значення адміністративної дистанції маршрутів протоколу RIP.

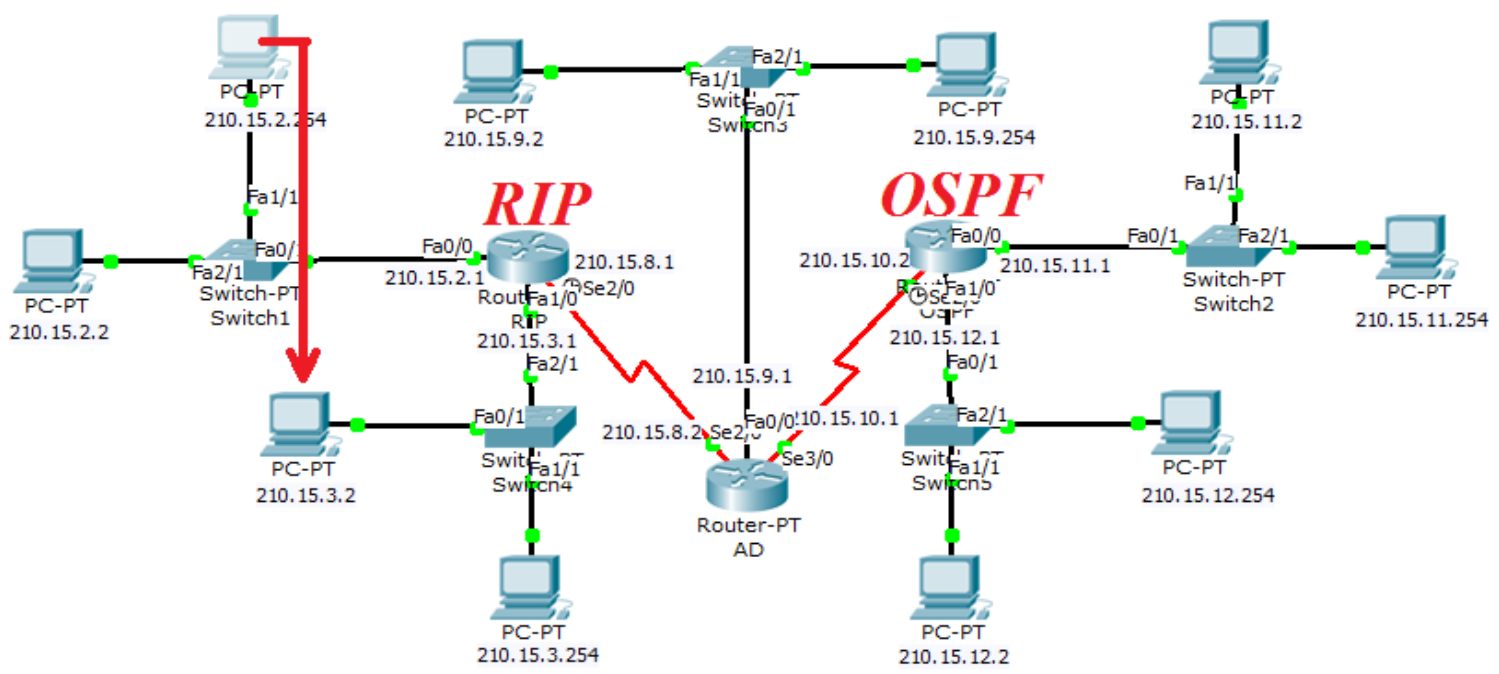

Рисунок 2 - Модель мережі, на якій вивчалася взаємодія протоколів маршрутизації RIP та OSPF

Після призначення $I P$-адрес усім портам маршрутизаторів мережі і налаштувань всіх мережних адаптерів комп'ютерів, налаштовуємо динамічну маршрутизацію RIP на маршрутизаторі $R I P$ та динамічну маршрутизацію $O S P F$ на маршрутизаторі $O S P F$. Щоб маршрутизатори RIP та OSPF мали можливість обмінюватися інформацією, на пристрої, що знаходиться між ними, під назвою $A D$, потрібно налаштувати маршрутизацію за обома протоколами: i $R I P$, i $O S P F$.

В результаті цих налаштувань таблиця маршрутизації маршрутизатора $A D$ показує, що 3 мережами маршрутизатора RIP він з'єднаний протоколом RIP, а 3 пристроєм під назвою $O S P F$ - за протоколом OSPF. 3 цього випливає, що існує взаємодія між будь-яким вузлом маршрутизатора $A D$ i будь-яким іншим вузлом мережі. Однак, між маршрутизаторами RIP та $O S P F$ зв'язок досі відсутній. Щоб він з'явився, на маршрутизаторі $A D$ треба налаштувати перерозподіл маршрутів RIP в $O S P F$ та навпаки. Команди, які це виконують, такі:
AD (config) \#router ospf 100 - ця команда вводить у режим конфігурації протоколу $O S P F$;

AD (config-router) \#redistribute rip metric 3

Тепер виконаємо перерозподіл в іншу сторону, щоб пристрої, які працюють за протоколом RIP також мали дані про маршрути протоколу $O S P F$.

$\mathrm{AD}$ (config) \#router rip - введена команда входить у режим конфігурації протоколу RIP;

AD (config-router) \#redistribute ospf 100 .

Тепер змінимо адміністративну дистанцію протоколу маршрутизації.

Як видно 3 таблиці маршрутизації, протокол $O S P F$ має менше значення адміністративної дистанції (110), ніж протокол RIP (120). Тому його маршрути мають пріоритет перед маршрутами протоколу RIP. Це означає, що доставкою пакетів по мережі буде займатися тільки протокол $O S P F$. Але інколи бувають випадки, що потрібно як основний протокол використовувати RIP чи інший 3 ще більшою адміністративною дистанцією. Для цієї мети можемо 
змінити стандартне значення адміністративної відстані на маршрутизаторі $A D$

AD (config) \#router rip

$\mathrm{AD}$ (config-router) \#distance 90

Для перевірки функціональності мережі, виконаємо команду tracert від вузла, підключеного до маршрутизатора $R I P$ до вузла, підключеного до маршрутизатора $O S P F$. Результат виконання команди показав, що пакет передався успішно, і це означає, що маршрутизація, перерозподіл маршрутів та зміна адміністративної дистанції виконані вірно, в результаті чого мережа функціонує правильно.
Схема 2. Побудова та налаштування мережі 3 взаємодією між протоколом маршрутизації $E I G R P$, статичною маршрутизацією i 3 підсумовуванням маршрутів

В середовищі CiscoPacketTracer побудуємо мережу 3 використанням трьох маршрутизаторів, яким присвоїмо назви: $E I G R P$ - той, який працюватиме 3 динамічною маршрутизацією за протоколом $E I G R P$, Static - той, на якому працюватиме статична маршрутизація та Summary - маршрутизатор, який з'єднуватиме два попередніх (рисунок 3). На останньому пристрої буде прослідковуватися автоматичне та адміністративне підсумовування маршрутів.

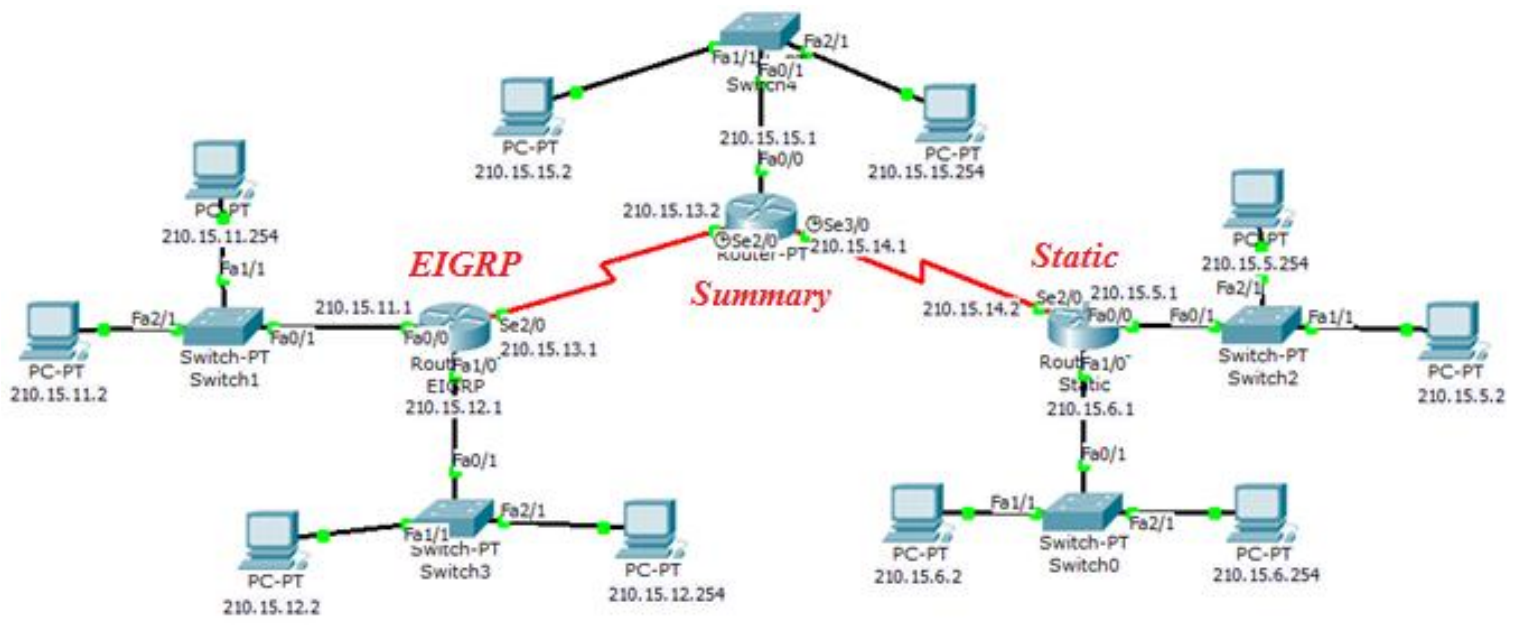

Рисунок 3 - Модель мережі з взаємодією між протоколом маршрутизації EIGRP, статичною маршрутизацією і з підсумовуванням маршрутів

Призначаємо IP-адреси усім портам маршрутизаторів мережі і налаштовуємо всі мережні адаптери комп'ютерів. Після цього налаштовуємо динамічну маршрутизацію EIGRP на маршрутизаторі EIGRP статичну маршрутизацію на маршрутизаторі Static. Щоб у подальшому маршрутизатори Static та EIGRP мали можливість також обмінюватися інформацією, на пристрої, що знаходиться між ними, під назвою Summary, потрібно налаштувати статичну маршрутизацію, а потім перерозподіл маршрутів Static в EIGRP. Для цього на маршрутизаторі Summary в режимі конфігурації протоколу EIGRP вводимо команди:

Summary(config)\#router eigrp 1

Summary (config-router) \#redistribute static Summary (config-router) \#end

Між вузлами 3 різною маршрутизацією з'явився зв'язок, але проблеми залишилися. Справа у тому, що протокол EIGRP може створити навантаження на мережу, якщо від усіх «зовнішніх» маршрутів одночасно почнуть пересилатися повідомлення на маршрутизатор EIGRP. У цій частині мережі дані оброблятимуться повільніше. Частина мережі зі статичною маршрутизацією та центральний маршрутизатор Summary такого навантаження не отримає. Адже пристрій Static взагалі не навантажується завдяки простоті статичної маршрутизації, а Summary працює також за статичною маршрутизацією, оскільки адміністративна відстань іiі значно менша за динамічну.

Найбільш широко підсумовування маршрутів використовується саме протоколом EIGRP. Автоматичне підсумовування в даному протоколі встановлено за замовчуванням. Тому часто при налаштуванні протоколу доводиться вимикати автоматичне підсумовування, щоб не виникало складностей. В даній схемі також необхідно його вимкнути. Так як IP-адреси підмереж нашої мережі повнокласові, то підсумовуватися автоматично нічого не буде, та для демонстрації роботи команди виконаємо дії:

Summary\#conf $t$

Summary(config) \#router eigrp 1

Summary (config-router) \#no auto-summary

Перевіримо таблицю маршрутизації маршрутизатора $E I G R P$ :

EIGRP\#sh ip route

D EX 210.15.5.0/24 [170/25632000] via

$210.15 .13 .2,00: 24: 03$, Serial2/0

D EX 210.15.6.0/24 [170/25632000] via 210.15.13.2, 00:24:03, Serial2/0

C 210.15.11.0/24 isdirectlyconnected, Fastethernet $0 / 0$

C 210.15.12.0/24 isdirectlyconnected, FastEthernet1/0

C 210.15.13.0/24 isdirectlyconnected, Serial2/0

D $210.15 .14 .0 / 24 \quad[\mathbf{9 0 / 2 1 0 2 4 0 0 0 ] ~ v i a ~}$

210.15.13.2, 00:24:03, Serial2/0

D $210.15 .15 .0 / 24[\mathbf{9 0 / 2 0 5 1 4 5 6 0 ]} \mathrm{via}$

210.15.13.2, 00:24:03, Serial2/0

Щоб зменшити навантаження на маршрутизатор $E I G R P$, якому доводиться підтримувати дві «внутрішніх» та дві «зовнішніх» гілки мережі по даному протоколу, треба об'єднати всі чотири адреси в одну за допомогою адміністративного підсумовування. 
Увімкнемо підсумовування всіх маршрутів протоколу в один, вказавши маску класу В, замість класу C.

Summary>en

Summary\#conf $t$

Summary(config)\#interface serial2/0

Summary(config-if) \#ip address

210.15 .13 .2255 .255 .255 .0

Summary (config-if) \#ip summary-address

eigrp 1210.15 .0 .0255 .255 .0 .0

Перевіряємо, які зміни сталися в таблиці маршрутизації:

EIGRP\#sh ip route

D $\quad 210.15 .0 .0 / 16[90 / 21024000]$ via

210.15.13.2, 00:01:51, Serial2/0

C 210.15.11.0/24 isdirectlyconnected, Fastethernet0/0

C $210.15 .12 .0 / 24$ isdirectlyconnected, Fastethernet1/0

C 210.15.13.0/24 isdirectlyconnected, Serial2/0

Замість чотирьох різних маршрутів тепер маємо один спільний маршрут за протоколом EIGRP. В деяких випадках таке підсумовування може бути корисним, а в деяких - навпаки шкідливим.

Наприклад, у разі, якщо маршрутизатору необхідно знати всю інформацію про складові мережі, володіти даними про їхні IP-адреси, то підсумовування їх виконувати не варто. Коли ж для маршрутизатора важлива лише сама інформація, а не точні дані про адресата, процедура підсумовування спростить умови функціонування мережі.

\section{Висновки}

У результаті проведеної роботи були змодельовані схеми комп'ютерних мереж, в яких налаштована сумісна робота різних протоколів маршрутизації. Були відмічені особливості налаштувань маршрутизаторів та особливості функціонування таких схем.

За результатами роботи були написані методичні вказівки для лабораторної роботи для студентів спеціальності «Комп'ютерні системи та мережі».

\section{Література}

1. Мазур А.С., Овчинников А. Л. Исследование Методов Маршрутизации. [Електронний ресурс]. - Режим доступу: http://ea.donntu.edu.ua.

2. Полукаров Д. Ю. Методы IP-маршрутизации на основе алгоритмов с использованием нечетких множеств. - Самара, 2007. [Електронний ресурс].

3. Устинов И. А. Адаптивная децентрализованная маршрутизация в цифровой сети с интеграцией служб общего назначения в условиях динамики топологии и трафика сети. - Владимир, 2009.[Електронний ресурс]. - Режим доступу: http://tekhnosfera.com

4. Остерлох Х. Маршрутизация в IP-сетях. Принципы, протоколы, настройка; пер. с англ. СПб: ООО "ДиаСофтЮП", 2002. - 512 с.

5. Работа сети с множеством протоколов маршрутизации [Електронний ресурс]. - Режим доступу: http://mcp1971.livejournal.com/9063.html.

6. $O S P F$. Настройка и проверка суммирования маршрутов [Електронний ресурс]. - Режим доступу: http://mcp1971.livejournal.com/7775.html.

7. Вопросы оценки управления маршрутами в производительности сети [Електронний ресурс]. - Режим доступу: http://mcp1971.livejournal.com/ 9593.html.

8. Протокол $E I G R P$ (усовершенствованный внутренний протокол маршрутизации шлюзов) [Електронний ресурс]. - Режим доступу: http://www.cisco.com/cisco/web/ support/ RU/9/92/92088_eigrp-toc.html\#theoryofoperation

Отримана в редакції 02.11.2017, прийнята до друку 08.12.2017

\title{
Features of Several Routing Protocols Interaction in a Complex Computer Network
}

\author{
I. S. Bobrikova ${ }^{凶}$, T. N. Barabash
}

Odesa National Academy of Food Technologies, 112, Kanatna str., Odesa, 65039, Ukraine

$\bowtie$ e-mail: bobrikova.irina@gmail.com

The study of operation features of several routing protocols at the same time on the same router and configuration features of such interaction is presented in the paper. The work was carried out in the Cisco Packet Tracer environment. The configuration of routers in different variants of complex networks construction with operation of several routing protocols was studied and observations as to how a certain setting affects the construction of the routing spreadsheet were made.

Keywords: router, routing protocol, complex networks, Cisco Packet Tracer

\section{References}

1. Mazur A. S., Ovchinnikov A. L. Issledovanie Metodov Marshrutizatsii. URL: http://ea.donntu.edu.ua.

2. Polukarov D. Yu. 2007. Metody IP-marshrutizatsii na osnove algoritmov s ispol'zovaniyem nechetkikh mnozhestv. [Electronic source].

3. Ustinov I. A. 2009. Adaptivnaya detsentralizovannaya marshrutizatsiya $\mathrm{v}$ tsifrovoy seti $\mathrm{s}$ integratsiyey sluzhb obshchego naznacheniya $\mathrm{v}$ usloviyakh dinamiki topologii $\mathrm{i}$ trafika seti. URL: http://tekhnosfera.com

4. Osterlokh Kh. 2002. Marshrutizatsiya v IP-setyakh. Printsipy, protokoly, nastroika; per. s angl. $\mathrm{SPb}, 512 \mathrm{p}$.
5. Rabota seti s mnozhestvom protokolov marshrutiza-tsii. URL: http://mcp1971.livejournal.com/9063.html.

6. OSPF. Nastroyka i proverka summirovaniya marshrutov. URL: http://mcp1971.livejournal.com/7775.html.

7. Voprosy otsenki upravleniya marshrutami v proizvoditel'nosti seti. http://mcp1971.livejournal.com/9593.html.

8. Protokol EIGRP (usovershenstvovannyy vnutrenniy protokol marshrutizatsii shlyuzov). URL: http://www.cisco. com/cisco/web/support/RU/9/92/92088 eigrptoc.html\#theoryofoperation

Received 02 November 2017 Approved 08 December 2017 Available in Internet 23 December 2017 